\title{
Comparison of Executive Functions and Difficulties in Emotional Regulation in Addicts with High and Low Borderline Personality Traits
}

\author{
Reza Mohammadzadeghan ${ }^{1 *}$
}

\section{ABSTRACT}

This study was performed aimed to compare the executive functioning and difficulties with emotional regulation in addicts with high and low borderline personality traits. The plan of the study was causal- comparative. The research sample population consisted of all men who had drug abuse in 2013 who referred to addiction centers. 80 addicted persons were selected by available sampling and by using questionnaire of borderline personality traits (STB) in two groups of 40 as abusers with high and low borderline traits. The Wisconsin Card Sorting Test and the scale of difficulty in emotional regulation of the two groups were performed. Then data were analyzed in SPSS Version 20 using multivariate analysis of variance (MANOVA) and test LSD. The results showed that addicts with a high proportion of borderline traits, have a poorer performance than addicts with low borderlines attributes in the Wisconsin Card Sorting Test and the number of retained in perseveration $(\mathrm{P}=0 / 010)$ and total error $(\mathrm{P}=0 / 002)$ is higher. Also abusers with higher borderline traits, have higher scores in the emotional difficulties regulation ( $\mathrm{P}=0 / 002)$ than addicts with low borderline of traits. The results showed that the addicts with a high boundary characteristic have poorer performance in executive functioning and higher levels of emotional difficulties in emotional regulation that this may be the result of the impact of drug dependency on their neurological function that may lead to weaker performance of these people compared to low borderline traits addicts.

Keywords: Executive Functioning, Difficulties In Emotion Regulation, Borderline Personality Traits, Addiction.

Borderline personality disorder is one of the most important public health problems which are associated with significant adverse consequences for individuals, families and communities. This disorder is identified with ongoing problems like emotional (such as anger), behavioral (hurting oneself), cognitive (decomposition) and interpersonal (relationships turbulent) (APA, 1994).

\footnotetext{
${ }^{1}$ M.A. In Psychology, University Of Tabriz, Tabriz, Iran

*Responding Author

(C) 2016 I M Reza; licensee IJIP. This is an Open Access Research distributed under the terms of the Creative Commons Attribution License (http://creativecommons.org/licenses/by/2.0), which permits unrestricted use, distribution, and reproduction in any Medium, provided the original work is properly cited.
} 


\section{Comparison of Executive Functions and Difficulties in Emotional Regulation in Addicts with High And Low Borderline Personality Traits}

Borderline personality disorder is strongly associated with drug abuse (APA, 2000; Millon \& Davis, 1996). This disorder is identified with features such as impulsivity, chronic feelings of emptiness, identity disturbance, lack of control of anger, intense and frequent mood changes, life-threatening behavior which starts in early adulthood (APA, 2000; Who , 1993a). Studies that have examined drug abuse patients, have shown that the rate of borderline personality disorder is in the range of $19 \%$ to more than $46 \%$ (Trull, Sher, Minks-Brown et al, 2000; Darke, Williamson, Ross et al, 2004b). Some studies have also suggested that more than 67 percent of people with borderline personality disorder, simultaneously have diagnostic criteria for a drug abuse disorder, however, when the diagnostic criteria for drug abuse as one of the borderline personality was omitted, this figure dropped to 57 percent of the population yet it is high value for borderline population (Linehan, Schmidt, Dimeff Et Al, 1999; Skodol, Gunderson, Pfohl Et Al, 2002).

Many researchers believe that people with borderline personality disorder are simultaneously qualified with diagnostic criteria for a drug abuse disorder than any other psychiatric disorder (excluding antisocial personality disorder) (Linehan et al, 1999). It also been proposed that individuals with borderline personality disorder begin using drugs in a younger age than those without the disorder (Links, Heslegrave, Mitton et al; 1995, Ross, Dermatis, Levounis et al, 2003). The studies have shown that the comorbidity of borderline personality disorder with drug abuse disorder both are associated with a worse prognosis disorders (Links et al; 1995). For example borderline personality disorder comorbidity among patients is relevant with higher levels of drug abuse (Darke, Ross, Williamson et al, 2005), a sharp increase in symptoms of drug abuse (Morgenstern, Langenbucher, Labouvie et al, 1997) and high-risk behaviors of drug use (Darke et al, 2005a).

Moreover, one of the most important factors affecting the drug abuse disorder in most researches (AguilarDeArcos, VerdejoGarcia, Ceverino etal,2008; Wilens, Martelon, Anderson etal,2013; Ch eetham Allen, Yucel etal,2010; Gonzalez, Zvolensky, Vujanovic et al, 2005; Dorard, Berthos, Phan et al, 2008) is emphasized on is the difficulty in emotional regulating. Which means mechanism of emotional regulating may be an important factor in the framework of disorders of drug abuse (see Lorberg, Wilens, Martelon et al, 2010). Specific definitions of emotional regulation difficulties are different in terms of researchers (Putnam and Silk, 2005). Despite the great number definitions for difficulty in emotional regulating, what appears to be the common definition is the emotional instability, emotional reactivity, lack of emotional self-regulating and irritability (Dorard, Berthos, Phan et al, 2008; Althoff, Ayer, Rettew et al, 2010a). Many findings have highlighted the role of difficulty in the emotional regulation of disorder of drug abuse (Aguilar De Arcos, Verdejo-Garcia, Ceverino etal, 2008; Cheetham Allen, Yucel et al, 2010). Also some evidences found that disorder of drug abuse has the highest level of difficulty in emotional regulation (Fox, Axelrod, Paliwal et al, 2007; Fox, Hong, Sinha et al, 2007). These 


\section{Comparison of Executive Functions and Difficulties in Emotional Regulation in Addicts with High And Low Borderline Personality Traits}

findings present higher levels of emotional disorder among dru abusers with borderline personality disorder features compared to abusers without borderline personality disorders.

In this regard, a hypothesis that has recently been discussed has emphasized the role of executive function impairment in drug abuse addiction (Lyvers, Leggio, Abenavoli et al, 2005). Although definitions vary, but executive functioning is generally called to a series of skills necessary to operate independently and objectively including higher levels neurodevelopment functions such as working memory, inhibitory control, organization, planning (Stuss, Benson, Clermont et al, 1986; Lezak, 1995) that are critical for successful adaptation because they facilitate the behaviors intended to goal and capacity to manage multiple stimuli or implementing requests (Fried and Smith, 2001; Alvarez and Emory, 2006; Noland, Singer, Arendt et al, 2003). In this regard, many studies examined the role of executive functions in drug abuse. Fields and Fullerton, 1974 suggested in a study that the neurological functioning of heroin addicts have significant difference with the control group and the condition of addicts is significantly disturbing. Also, Noel, Van Der Linden, d'Acremont et al, 2007 proposed that addicts have serious flaws in executive functions such as Response Inhibition, Decision making and problem solving, Abstract Reasoning and Shifting Attention; these damage are likely related to the structural and functional abnormalities in the frontal part (Moselhy, Tavares, Da Silva et al, 2004). Also Korin, Aubin, Craving et al, 2010a demonstrated that heroin addicts show more in preseveration retaining error and rotation in pattern designing and limited use of space in paper compared to non-addicts.

Meanwhile according to the rapid growth of addiction in society and its impact on overall performance of individual and social, knowledge and careful evaluation of different aspects of the disease may help to clarify the different variables, so with regard to issues suggested above and the importance of subject, the present study assesses and compares the executive functions and the difficulty in emotional regulation of abusers with high and low borderline personality traits.

\section{METHOD}

Study design was causal - comparative. The research statistical population included all drug abusers in Khoy who have referred to addiction rehabilitation centers (4 centers) in 2013. From each center, 20 patients were selected availably and totally 80 people formed the sample volume. To separate the groups, borderline personality traits questionnaire (STB Collection) was used. So that among all the people referred to centers, 40 were selected as people with high borderline personality who received a score higher than cut-off point in questionnaire of borderline personality traits and 40 others who referred to the centers were selected as individuals with low borderline personality traits who received scores below the cut-off point 10 . Finally after separating groups, the test Wisconsin cards and the scale of difficulty on emotional regulation were carried out on them. Two groups were matched in terms of demographic characteristics such as gender, marital status, age, education and ethnicity. Before analyzing the 


\section{Comparison of Executive Functions and Difficulties in Emotional Regulation in Addicts with High And Low Borderline Personality Traits}

data, the size of missing values were modified by substituting mean method and then data were analyzed in SPSS20 using descriptive statistics, multivariate analysis of variance (MANOVA) and test paired comparisons of LSD.

\section{Measures}

\section{Borderline personality traits scale (Schizotypal Trait Questionnaire-B Form)}

Borderline personality traits scale (STB) is part of the questionnaire of schizotypal traits and borderline personality traits scale that is created by Claridge and Broks (1984) and it is answered by a yes/no. Yes receives one and No receives zero. Mohammadzadeh et al (2005) by complying edited version of this test with the criteria of recognition and statistical guide and (DSM-IV 20) have introduced 20 articles which assess the 3 elements of Disappointment (7 articles), impulsivity (7 articles) and dissociative symptoms and stress-related paranoid (6 Articles). The reliability coefficients have been reported by re-test in four weeks for the total scale of borderline personality $84 \%$ and despair subscales $53 \%$, impulsivity $72 \%$ and analytical and paranoid symptoms related to stress $50 \%$. Coefficient alpha for the total scale is $77 \%$ and for subscales despair is $64 \%$, and for impulsivity $58 \%$ and symptoms analysis and stress-related paranoid is $57 \%$. In the present study, the alpha coefficient for the total scale obtained $75 \%$ (Mohammad zadeh et al, 2005).

\section{Wisconsin Card Sorting Test}

This test evaluates the abstraction ability and cognitive strategies changes in response to feedback from the environment (Cavallaro, Cavedini, Mistretta et al, 2003). The test consists of 64 anomalous cards with different forms (triangle, star, cross, circle) and different colors. To run the test, at first 4 pattern cards are inserted in front of the subject. Examiner first considers the color as the main category without informing this principle to subject and ask him to insert rest of the cards under 4 sample cards one by one. After each attempt, subjects are told if his placement is correct or not. If the subject is able to perform successive correct classification of 10 categories, the principle of classification will be changed and the next would be altered. Changing of principle is only done by Yes and No feedback. Thus, the previous correct answer in new principle is deemed as inappropriate answer. The next principle is number and then three principles are repeated again, respectively. Test stops when the subject could successfully classify 6 classes. The validity of this test has been reported for cognitive deficits following brain damage over 0/86 (Stuss et al, 1986). The reliability of the test were reported according to the agreed ratio of assessors 0/83 (Spreen and Stauss, 1991) and in Iranian sample with using retest $0 / 85$ has been reported (Naderi, 1994).

\section{Scale of Difficult In Emotion Deregulation}

Scale of Difficult in Emotion Deregulation (DERS) is a 36-item instrument made by Graz and Roemer (2004) and scoring the items is done through a Likert 5 degrees. Higher scores indicate greater difficulty in in Emotion Deregulation. The scale measures the normal level of difficulty 


\section{Comparison of Executive Functions and Difficulties in Emotional Regulation in Addicts with High And Low Borderline Personality Traits}

in emotion deregulation of people in six domains including: 1 . Non-acceptance of emotional responses (NONACCEPT), 2. Difficulty in engaging in the directed behavior (GOALS), 3. Problem with impulse control (IMPULSE), 4. The lack of emotional awareness (AWARE), 5. Limited access to emotion regulation strategies (STRATEGIES) and 6. Lack of emotional clarity (CLARITY ). The reliability coefficients of total scale using Internal consistency is $93 \%$ and for each of the six sub-scales of emotional difficulties of Cronbach alpha coefficients is greater than $80 \%$. Retest reliability coefficient over a period of 4 to 8 weeks is achieved $88 \%$. Also in this study is achieved using Cronbach's alpha reliability coefficient of $86 \%$.

\section{RESULTS}

Table (1) presented the mean and standard deviation scores of the groups participating in the Wisconsin Card and the difficulty in emotion discipline. As the results show average addict group with high borderline personality traits in all the variables is higher than the average of addict group with low borderline personality traits.

Table1. Descriptive statistics (mean and standard deviation) between the two groups in Wisconsin Card and difficulty in emotion Regulation components of them

\begin{tabular}{|c|c|c|c|c|c|c|c|}
\hline Variable & Groups & $\begin{array}{l}\text { The mean } \\
\text { (standard } \\
\text { deviation) }\end{array}$ & $\mathbf{N}$ & Variable & Groups & $\begin{array}{l}\text { The mean } \\
\text { (standard } \\
\text { deviation) }\end{array}$ & $\mathbf{N}$ \\
\hline \multirow{2}{*}{$\begin{array}{l}\text { Preseveration } \\
\text { Error }\end{array}$} & $\begin{array}{l}\text { High borderline } \\
\text { trait }\end{array}$ & $8 / 40(5 / 40)$ & \multirow{2}{*}{80} & \multirow{2}{*}{ AWARE } & $\begin{array}{l}\text { High } \\
\text { borderline } \\
\text { Traits }\end{array}$ & $85 / 16(05 / 4)$ & \multirow{2}{*}{80} \\
\hline & $\begin{array}{l}\text { Low borderline } \\
\text { traits }\end{array}$ & $02 / 5(05 / 6)$ & & & \begin{tabular}{|c|}
$\begin{array}{c}\text { Low borderline } \\
\text { traits }\end{array}$ \\
\end{tabular} & $62 / 16(42 / 4)$ & \\
\hline \multirow{2}{*}{$\begin{array}{l}\text { The Total } \\
\text { Error }\end{array}$} & $\begin{array}{l}\text { High borderline } \\
\text { trait }\end{array}$ & $\begin{array}{l}92 / 13 \\
(24 / 6) \\
\end{array}$ & \multirow{2}{*}{80} & \multirow{2}{*}{$\begin{array}{c}\text { STRATEGI } \\
\text { ES }\end{array}$} & \begin{tabular}{|c|} 
High \\
borderline trait \\
\end{tabular} & $36 / 24(63 / 6)$ & \multirow{2}{*}{80} \\
\hline & $\begin{array}{l}\text { Low borderline } \\
\text { traits }\end{array}$ & $15 / 9(19 / 7)$ & & & $\begin{array}{c}\text { Low borderline } \\
\text { traits }\end{array}$ & $74 / 21(44 / 6)$ & \\
\hline \multirow{2}{*}{ Nonaccept } & $\begin{array}{l}\text { High borderline } \\
\text { trait }\end{array}$ & $\begin{array}{l}73 / 17 \\
(30 / 5) \\
\end{array}$ & \multirow{2}{*}{80} & \multirow{2}{*}{ CLARITY } & \begin{tabular}{|c|} 
High \\
borderline trait \\
\end{tabular} & 13/14(94/2) & \multirow{2}{*}{80} \\
\hline & $\begin{array}{l}\text { Low borderline } \\
\text { traits }\end{array}$ & $\begin{array}{l}57 / 17 \\
(34 / 5)\end{array}$ & & & \begin{tabular}{|c|}
$\begin{array}{c}\text { Low borderline } \\
\text { traits }\end{array}$ \\
\end{tabular} & $48 / 11(21 / 4)$ & \\
\hline \multirow{2}{*}{ Goals } & $\begin{array}{l}\text { High borderline } \\
\text { trait }\end{array}$ & $\begin{array}{l}71 / 17 \\
(19 / 4)\end{array}$ & \multirow{2}{*}{80} & \multirow{4}{*}{$\begin{array}{l}\text { Regulation } \\
\text { of emotion } \\
\text { (total) }\end{array}$} & High & & \multirow{4}{*}{80} \\
\hline & $\begin{array}{l}\text { Low borderline } \\
\text { traits }\end{array}$ & $\begin{array}{l}29 / 15 \\
(33 / 4)\end{array}$ & & & borderline trait & $8 / 1109(04 / 15)$ & \\
\hline \multirow{2}{*}{ Impulse } & $\begin{array}{l}\text { High borderline } \\
\text { trait }\end{array}$ & $\begin{array}{l}98 / 19 \\
(99 / 4) \\
\end{array}$ & \multirow{2}{*}{80} & & \multirow{2}{*}{$\begin{array}{c}\text { Low borderline } \\
\text { traits }\end{array}$} & \multirow{2}{*}{$01 / 98(34 / 18)$} & \\
\hline & $\begin{array}{l}\text { Low borderline } \\
\text { traits }\end{array}$ & $\begin{array}{l}44 / 16 \\
(08 / 5)\end{array}$ & & & & & \\
\hline
\end{tabular}




\section{Comparison of Executive Functions and Difficulties in Emotional Regulation in Addicts with High And Low Borderline Personality Traits}

Following in order to further investigate the significant difference between groups, first the assumption of normal distribution of the test group Kolmogorov - Smirnov was checked that $\mathrm{z}$ score was not significant for neither groups in two tests of executive function and emotional difficulty in discipline, and this means that the distribution of these groups has no significant difference with normal distribution, thus normal assumption is established (Table 2).

Table2. The results of Kolmogorov - Smirnov test in both groups in Wisconsin Card and emotional Regulation difficulties test

Table2. The results of Kolmogorov - Smirnov test

\begin{tabular}{|l|l|l|}
\hline Kolmogorov - Smirnov test & Z & Sig. \\
\hline Wisconsin Card (total error) & $0 / 559$ & $1 / 118$ \\
\hline difficulty in emotional regulation (total) & $0 / 913$ & $0 / 14$ \\
\hline
\end{tabular}

Also in order to use the ANOVA assumption of homogeneity of variances were studied using Leven test. Based on the results, the homogeneity of variances assumptions in Wisconsin Card $[F=1 / 138, P=0 / 289]$ and emotional regulation difficulties $[F=0 / 441, P=0 / 509]$ and their components in both groups were confirmed, the test was not significant for none of the variables. So after ensuring that the data is examined have all conditions using analysis of variance, this test was used.

Results of multivariate analysis in Table 3 shows that there is a significant difference between two drug groups with high and low borderline personality traits at least according to one of the variables. According to Table (3) levels of significance for all tests is authorized using multivariate analysis of variance. Thus, in order to evaluate the mean difference between two groups in the Wisconsin Card and emotional discipline difficulty and its component, the multivariate ANOVA were used and its results were reported in the table (4).

Table 3: Results of multivariate variance analysis for two groups

\begin{tabular}{|l|l|l|l|}
\hline Name of test & Value & F & Sig. \\
\hline Pillai's trace & $0 / 289$ & $3 / 155$ & $0 / 003$ \\
\hline Wilks, Lambda & $0 / 711$ & $3 / 155$ & $0 / 003$ \\
\hline Hotelling's trace & $0 / 406$ & $3 / 155$ & $0 / 003$ \\
\hline Roy's largest root & $0 / 406$ & $3 / 155$ & $0 / 003$ \\
\hline
\end{tabular}


Table 4: Results of multivariate variance analysis of the two groups in difficulty of emotional discipline test, Wisconsin Card and its components

\begin{tabular}{|l|l|l|l|l|l|l|}
\hline $\begin{array}{l}\text { Variables } \\
\text { source }\end{array}$ & Dependent variable & Square & df & Mean & F & Sig. \\
\hline \multirow{5}{*}{ Group } & Preseveration Error & $22 / 81$ & 1 & $227 / 81$ & $6 / 918$ & $0 / 010$ \\
\cline { 2 - 7 } & The Total Error & $45 / 01$ & 1 & $456 / 01$ & $10 / 04$ & $0 / 002$ \\
\hline \multirow{5}{*}{} & Nonaccept & $0 / 473$ & 1 & $0 / 473$ & $0 / 01$ & $0 / 898$ \\
\cline { 2 - 7 } & Goals & $0 / 117$ & 1 & $117 / 0$ & $6 / 42$ & $0 / 013$ \\
\cline { 2 - 7 } & Impulse & $251 / 24$ & 1 & $251 / 24$ & $9 / 90$ & $0 / 002$ \\
\cline { 2 - 7 } & Aware & $1 / 103$ & 1 & $1 / 103$ & $0 / 06$ & $0 / 805$ \\
\cline { 2 - 7 } & Strategies & $137 / 15$ & 1 & $137 / 15$ & $3 / 207$ & $0 / 077$ \\
\cline { 2 - 7 } & Clarity & $140 / 45$ & 1 & $140 / 45$ & $10 / 62$ & $0 / 002$ \\
\cline { 2 - 7 } & $\begin{array}{l}\text { Regulation Of Emotion } \\
\text { (Total) }\end{array}$ & $2815 / 00$ & 1 & $2815 / 00$ & $9 / 99$ & $0 / 002$ \\
\hline
\end{tabular}

As shown in Table (4) there is a significant difference between the two groups of variables of retaining in preseveration error $[\mathrm{F}=6 / 918, \mathrm{P}=0 / 010]$, The total error $[\mathrm{F}=10 / 04, \mathrm{P}=0 / 002]$ and disruption of the targeted behavior $[F=6 / 24, P=0 / 013]$, Impaired impulse control [F $=9 / 90, P=0 / 002]$, difficulty in emotional discipline $[F=9 / 99, P=0 / 002]$. But no significant difference was observed in the rejection variables of emotional responses $[F=0 / 017, P$ $=0 / 898]$, Lack of emotional awareness $[\mathrm{F}=0 / 061, \mathrm{P}=0 / 805]$, Poor emotional adjustment strategies $[\mathrm{F}=3 / 20, \mathrm{P}=0 / 077]$. Therefore $\mathrm{LSD}$ post hoc test was used to examine the differences of the groups and the results are presented in Table 5. As paired comparisons of test results LSD represents, there is a significant difference between the average of two groups in variables purposeful behavior disorder, impaired impulse control, lack of emotional clarity and emotional level of difficulty in level of 0/05, and drug addicts with high borderline personality traits have higher score in these variables than abusers with low borderline personality traits but in rejection of emotional responses, lack of emotional awareness and emotional adjustment strategies variables there is no significant difference between the two groups. Also, according to retaining in preseveration error variables and total error there is a significant difference between the two groups at $0 / 05$, it means that the scores of retaining in preseveration error and total error in drug addicts with high traits of borderline is more compared to low borderline personality traits. (Table 5) 
Comparison of Executive Functions and Difficulties in Emotional Regulation in Addicts with High And Low Borderline Personality Traits

Table 5: Results of the post hoc LSD test to compare the paired groups

\begin{tabular}{|c|c|c|c|c|c|}
\hline \multicolumn{3}{|l|}{ Variable } & \multirow{2}{*}{$\begin{array}{c}\begin{array}{c}\text { Differences } \\
\text { in Average }\end{array} \\
3 / 37^{*}\end{array}$} & \multirow{2}{*}{$\begin{array}{c}\text { Std.error } \\
1 / 28\end{array}$} & \multirow{2}{*}{$\begin{array}{l}\text { Sig. } \\
0 / 010\end{array}$} \\
\hline $\begin{array}{l}\text { Preseveration } \\
\text { Error }\end{array}$ & High borderline trait & $\begin{array}{c}\text { Low borderline } \\
\text { trait }\end{array}$ & & & \\
\hline The Total Error & High borderline trait & $\begin{array}{c}\text { Low borderline } \\
\text { trait }\end{array}$ & $4 / 77^{*}$ & $1 / 50$ & $0 / 002$ \\
\hline Nonaccept & High borderline trait & $\begin{array}{c}\text { Low borderline } \\
\text { trait }\end{array}$ & $0 / 15$ & $1 / 19$ & $0 / 898$ \\
\hline Goals & High borderline trait & $\begin{array}{c}\text { Low borderline } \\
\text { trait }\end{array}$ & $2 / 14^{*}$ & $0 / 95$ & $0 / 013$ \\
\hline Impulse & High borderline trait & $\begin{array}{l}\text { Low borderline } \\
\text { trait }\end{array}$ & $3 / 54^{*}$ & $1 / 12$ & $0 / 002$ \\
\hline Aware & High borderline trait & $\begin{array}{c}\text { Low borderline } \\
\text { trait }\end{array}$ & $0 / 235$ & $0 / 950$ & $0 / 805$ \\
\hline Strategies & High borderline trait & $\begin{array}{c}\text { Low borderline } \\
\text { trait }\end{array}$ & $2 / 61$ & $1 / 46$ & $0 / 077$ \\
\hline Clarity & High borderline trait & $\begin{array}{c}\text { Low borderline } \\
\text { trait }\end{array}$ & $2 / 65^{*}$ & $0 / 813$ & $0 / 002$ \\
\hline $\begin{array}{l}\text { Regulation Of } \\
\text { Emotion (Total) }\end{array}$ & High borderline trait & $\begin{array}{l}\text { Low borderline } \\
\text { trait }\end{array}$ & $11 / 86^{*}$ & 3/75 & $0 / 002$ \\
\hline
\end{tabular}

\section{CONCLUSIONS}

Abusers with high borderline personality traits have lower performance in the Wisconsin Card Sorting Test compared to abusers with low borderline personality traits. The difference between the two groups' performances in executive functioning (retaining in preseveration error and total error) is significant. The study is consistent with the findings of Luers and colleagues (2005), Fields and Fullerton (1974), Null \& et al (2007), Morly et al (2004) and Corinne (2010). In this regard, Ardilla et al (2007) suggest that the drug dependency caused damage on cognitive functions including problem solving Planning, Organization, Learning new things, spatial visual abilities, cognitive flexibility and skills to Remember. Also, the Einstein and Shaffer (1993) have suggested that drug addiction can lead to defects in seven neurological areas, including reducing the spontaneity, the behavioral changes or psychological problem, problem in preserving attention, impulsivity, disrupting social consciousness, disruption of insight, disrupting abstract reasoning. These disorders are in seven areas in the frontal cortex of executive dysfunction (especially dysfunction of anterior cingulate and prefrontal cortex (Fishbein, Eldreth, Hyde et al, 2005; Ersche, Roiser, Clark et al, 2005) that can be divided into three major areas of attention, impulse control, flexibility and abstract reasoning. At this point according to model Weinstein and Shaffer (1993), Pao et al (2002) suggest that drugs 


\section{Comparison of Executive Functions and Difficulties in Emotional Regulation in Addicts with High And Low Borderline Personality Traits}

(e.g., heroin which is a potent analgesic and sedative) can cross the Blood-Brain BarrierBBB led to significant neurodevelopmental effects in attention, impulse control and mental flexibility and abstract reasoning.

Other findings of this study indicate that the drug abusers with high borderline personality traits have higher scores in the variable of difficulty in emotional discipline compared to low borderline personality traits and there was a significant difference between two groups. These findings are consistent with the findings of Stasi and colleagues (1986), Fried et al (2001), Nuland et al (2003), Field et al (1974), Null et al(2007), Muzly and colleagues (2004). In support of these findings one can say that difficulty in regulating emotions is tied up with many mental disorders. In accordance with the views of Grass (1998b) emotional regulation difficulties proposed in many problems is involved in Diagnostic and Statistical Manual of the American Psychiatric Association - DSM, so that it is involved in more than $50 \%$ of axis I disorders and in all axis II disorder. Therefore difficulty emotional regulation is considered as obvious symptom of psychopathology in many disorders (Beauchaine, Gatzke -Kopp, Mead, 2006).

Also emotional adjustment can highly interfere with symptoms of disorder and individual ability to deal with. For example, difficulty in negative regulating emotions can also be related to internalizing disorders, such as anxiety and depression, and with externalizing disorders such as drug abuse and aggression, so difficulty in setting a negative emotion such as anger may lead to external disturbances such as acting out that this acting out can likely lead to disorders such as drug abusing in stressful situations (Gross, 1998b). Also in support of these findings, some researchers have proposed that drug use may be a mechanism to regulate emotion (Mirin, Weiss, Michael, 1987; Hayes, Wilson, Gifford et al, 1996).

In addition to the above, the results of this study highlight a potentially useful therapeutic target in drug abuse population (difficulty in emotional regulation). So that findings know the difficulty in emotional discipline as the mediating link between drug abusers and comorbidity of borderline personality traits (Linehan et al, 1999; Linehan, Dimeff, Reynolds et al, 2002). So treating the symptoms and borderline personality disorder widely, and focused treatment on reducing the difficulty in emotional discipline among drug abusers with comorbidity of borderline personality traits may be useful in reducing drug use. As was mentioned research literature suggests that drug use may be a function of emotional adjustment (Mirin et al, 1987; Hayes et al, 1996).

Noting the limitations of the study such limitations in generalizing results to the entire range of drug addicts because of variety in drug use and the comorbidity with other disorders as well, except for the mentioned items and opposition of mental disorders with addiction interaction, it is suggested that future studies will be carried out by considering the addiction type and comorbid disorders careful control. 


\section{Comparison of Executive Functions and Difficulties in Emotional Regulation in Addicts with High And Low Borderline Personality Traits}

\section{Acknowledgement}

I sincerely appreciate all partners, participants and patients of addiction clinics in the city of Khoy (Rahe Sabz, Shafa, Atiye and Baran) and all that were included in this study.

\section{REFERENCES}

Aguilar de Arcos, F., Verdejo-Garcia, A., Ceverino, A., Montanez-Pareja, M., Lopez- Juarez, E., Sanchez-Barrera, M., Lopez-Jimenez, A., Perez-Garcia, M., PEPSA Team. 2008. Dysregulation of emotional response in current and abstinent heroin users: negative heightening and positive blunting. Psychopharmacology (Berl).198, 159-166.

Althoff, R. R., Ayer, L. A., Rettew, D. C., Hudziak, J. J. 2010a. Assessment of dysregulated children using the Child Behavior Checklist: a receiver operating characteristic curve analysis. Psychol Assess, 22, 609-617.

Alvarez, J. A., Emory, E. 2006. Executive function and the frontal lobes: a meta-analytic review. Neuropsychol Rev, 16,17-42.

American Psychiatric Association. 1994. Diagnostic and statistical manual of mental disorders, 4th ed. Washington: DC7Author.

American Psychiatric Association. 2000. Diagnostic and Statistical Manual of Mental Disorders, 4th ed. (text revision).Washington. DC.

Ardila, P., Perez, J., Sanches, M., Peluso, M. A., Glahn, D., Soares, J. C. 2007. Impulsivity and bipolar disorder". Europiann Neuropsychopharmacology,17,313-20.

Beauchaine, T. P., Gatzke-Kopp, L., Mead, H. K. 2006. Polyvagal theory and developmental psychopathology: Emotion dysregulation and conduct problems from preschool to adolescence. Biological Psychology.; [Epub ahead of print]. Retrieved October 21, 2006, from http://www.ncbi.nlm.nih.gov/entrez/query.fcgi?db=pubmed\&cmd=Search \&itool=pubmed_AbstractPlus \& term=\%22MeadHK\%22\%5BAuthor\%5D.

Cavallaro, R., Cavedini, P., Mistretta, P., Bassi, T., Angelone, S. M., Ubbiali, A., et al. 2003. Basal-corticofrontal circuits in schizophrenia and obsessive-compulsive disorder: a controlled, double dissociation study. Biological Psychiatry, 54, 437-443.

Cheetham, A., Allen, N. B., Yucel, M., Lubman, D. I. 2010. The role of affective dysregulation in drug addiction. Clin Psychol Rev, 30, 621-634.

Claridge, G., Broks, P. 1984. Schizotypy and hemisphere function: Theoretical considerations and the measurement of schizotypy . Pers Indiv Diff, 5,633-648.

Darke, S., Ross, J., Williamson, A., Teesson, M. 2005. The impact of borderline personality disorder on 12-month outcomes for the treatment of heroin dependence. Addiction,100,1121-30.

Darke, S., Williamson, A., Ross, J., Teesson, M., Lynskey, M. 2004b. Borderline personality disorder, antisocial personality disorder and risk-taking among heroin users: findings from the Australian Treatment Outcome Study (ATOS). Drug and Alcohol Dependence, 74,77-83. 


\section{Comparison of Executive Functions and Difficulties in Emotional Regulation in Addicts with High And Low Borderline Personality Traits}

Dorard, G., Berthoz, S., Phan, O., Corcos, M., Bungener, C. 2008. Affect dysregulation in cannabis abusers: a study in adolescents and young adults. Eur. Child Adolesc Psychiatry, 17, 274-282.

Ersche, KD., Roiser, J. P., Clark, L., London, M., Robbins, T. W., Sahakian, B. J. 2005. Punishment Induces Risky Decision Making In Methadone Maintained Opiate Users But Not In Heroin Users Or Healthy Volunteers. Neuropsychopharmacology, 30, 2115-2124.

Fields, F. R. J., Fullerton, J. R. 1974. The influence of heroin addiction on neuropsychological functioning. Newsletter of Research in Mental Health and Behavioral Science,16,20-25.

Fishbein, D. H., Eldreth, B., Hyde, C., Matochik, J., London, E., Contoreggi, C., Kurian, V., Kimes, A., Breeden, A., Grant, S. 2005. Risky Decision Making And The Anterior Cingulated In Abstinent Drug Addicts And Nondrug Users. Brain Research, 23, 119136.

Fox, H. C., Axelrod, S. R., Paliwal, P., Sleeper, J., Sinha, R. 2007. Difficulties in emotion regulation and impulse control during cocaine abstinence. Drug Alcohol Depend, 89,298301.

Fox, H. C., Hong, K. A., Sinha, R. 2007. Difficulties in emotion regulation and impulse control in recently abstinent alcoholics compared with social drinkers. Addict Behav, 33, 388-94.

Fried, P. A., Smith, A. M. 2001. A literature review of the consequences of prenatal marihuana exposure. An emerging theme of a deficiency in aspects of executive function. Neurotoxicol Teratol, 23, 1-11.

Gonzalez, A., Zvolensky, M. J., Vujanovic, A. A., Leyro, T. M., Marshall, E. C. 2005. An evaluation of anxiety sensitivity, emotional dysregulation, and negative affectivity among daily cigarette smokers: relation to smoking motives and barriers to quitting. J Psychiatr Res, 43, 138-147.

Gratz, K. L., Roemer, L. 2004. Multidimensional assessment of emotion regulation and dysregulation: development, factor structure, and initial validation of the Difficulties in Emotion Regulation Scale. Journal of Psychopathology and Behavioral Assessment, 26,41-54.

Gross, J. J. 1998b. The emerging field of emotion regulation: An integrative review. Review of General Psychology, 2, 271-299.

Hayes, S. C., Wilson, K. G., Gifford, E. V., Follette, V. M., Strosahl, K. 1996. Experiential avoidance and behavioral disorders: a functional dimensional approach to diagnosis and treatment. J Consult Clin Psychol. 64, 1152-68.

Korin, M., Aubin, H. J. b. 2010. Craving's place in addiction theory: Contributions of the major models. Neuroscience and Biobehavioral Reviews, 34, 606-623.

Lezak, M. D. 1995. Neuropsychological assessment. 3rd ed. New York: Oxford University Press.

Linehan, M. M., Dimeff, L. A., Reynolds, S. K., Comtois, K. A., Welch, S. S., Heagerty, P. 2001. Dialectical behavior therapy versus comprehensive validation plus 12-step for the 


\section{Comparison of Executive Functions and Difficulties in Emotional Regulation in Addicts with High And Low Borderline Personality Traits}

treatment of opioid dependent women meeting criteria for borderline personality disorder. Drug Alcohol Depend, 67,13-26.

Linehan, M. M., Schmidt, H., Dimeff, L. A., Craft, J. C., Kanter, J., Comtois, K. A. 1999. Dialectical behavior therapy for patients with borderline personality disorder and drugdependence. American Journal on Addictions, 8, 279-292.

Links, P. S., Heslegrave, R. J., Mitton, J. E., van Reekum, R., Patrick, J. 1995. Borderline personality disorder and substance abuse: Consequences of comorbidity. Canadian Journal of Psychiatry, 40, 9-14.

Lorberg, B., Wilens, T. E., Martelon, M., Wong, P., Parcell, T. 2010. Reasons for substance use among adolescents with bipolar disorder. Am J Addict,19, 474-480.

Lyvers, G., Leggio, L., Abenavoli, L., Gasbarrini, G. 2005. Neurobiochemical and clinical aspects of craving in alcohol addiction: A review. Addictive Behaviors, 30, 1209-1224.

Millon, T., Davis, R. D. 1996. Disorders of Personality. DSM IV and Beyond. New York: John Wiley \& Sons.

Mirin, S. M., Weiss, R. D., Michael, J. 1987. Psychopathology in substance users: diagnosis and treatment. Am J Drug Alcohol Abuse, 14,139-57.

Mohammad Zadeh, A., Goudarzi, M. A., Taghavi, M. R., Molazadeh, J. 2005. the study of factor structure, validity, reliability and standardization of borderline personality scale (STB) in Shiraz. The Quarterly Journal of Fundamentals of Mental Health, 7,75-89. [Persian]

Morgenstern, J., Langenbucher, J., Labouvie, E., Miller, K. J. 1997. The comorbidity of alcoholism and personality disorders in a clinical population: prevalence and relation to alcohol typology variables. J Abnorm Psychol, 106,74-84.

Moselhy, S. S., Tavares, H., da Silva Lobo, D. S., Galetti, A. M., Gentil, V. 2004. Pathological gambling, gender, and risk-taking behaviors. Addictive Behaviors, 29, 1231-1235

Naderi, N. 1994. A study of information processing and some of neuropsychological functions patient with obsessive-compulsive disorder. Tehran: psychiatry institute of Tehran; [In Persian].

Noël, X., Van der Linden, M., d'Acremont, M., Bechara, A., Dan, B., Hanak, C., Verbanck, P. 2007. Alcohol cues increase cognitive impulsivity in individuals with alcoholism. Psychopharmacology, 192, 291-8.

Noland, J. S., Singer, L. T., Arendt, R. E., Minnes, S., Short, E. J., Bearer, C. F. 2003. Executive functioning in preschool-age children prenatally exposed to alcohol, cocaine, and marijuana. Alcohol Clin Exp Res, 27,647-56.

Pau, W. H. C., Lee, M. C. T., Chan, F. S. F. 2002. The Impact Of Heroin On Frontal Executive Functions. Archives Of Clinical Neuropsychology,17,663-670.

Putnam, K. M., Silk, K. R. 2005. Emotion dysregulation and the development of personality disorder. Developmental Psychopathology,17,899-925. 
Ross, S., Dermatis, H., Levounis, P., Galanter, M. 2003. A comparison between dually diagnosed inpatients with and without Axis II comorbidity and the relationship to treatment outcome. American Journal of Drug and Alcohol Abuse, 29, 263-279.

Skodol, A. E., Gunderson, J. G., Pfohl, B., Widiger, T. A., Livesley, W. J., Siever, L. J. 2002. The borderline diagnosis I: Psychopathology, comorbidity, and personaltity structure. Biological Psychiatry, 51, 936-950.

Spreen, O., Strauss, E. 1991. A compendium of neuropsychological tests. Oxford University Press: New York.

Stuss, D. T., Benson, D. F., Clermont, R., Della Malva, C. L., Kaplan, E. F., Weir, W. S. 1986. Language functioning after bilateral prefrontal leukotomy. Brain Lang, 28,66-70

Trull, T. J., Sher, K. J., Minks-Brown, C., Durbin, J., Burr, R. 2000. Borderline personality disorder and substance use disorders: a reviewand integration. Clinical Psychology Review, 20, 235-253.

Weinstein, C. S., Shaffer, H. J. 1993. Neurocognitive aspects of substance abuse treatment:Apsychotherapist's primer. Psychotherapy, 30, 317-333.

Wilens, E. T., Martelon , M. K., Anderson, P. J., Abrahamson, R. S., Biederman, J. 2013. Difficulties In Emotional Regulation And Substance Use Disorders: A Controlled Family Study Of Bipolar Adolescents. Drug And Alcohol Dependence, 132,114- 121

World Health Organization. 1993a. The ICD-10 Classification of Mental and Behavioural Disorders. Vienna: World Health Organization. 